\title{
ethic@ \\ O DEBATE HABERMAS VERSUS APEL SOBRE A ÉTICA DO DISCURSO: RECONSIDERAÇÃO DAS RAZÕES DA DIVERGÊNCIA
}

\section{THE DEBATE BETWEEN HABERMAS AND APEL ON DISCOURSE ETHICS: RECONSIDERATION OF THE REASONS FOR THE DIVERGENCE}

\author{
MARINA VELASCO ${ }^{1}$ \\ (UFRJ/Brasil)
}

\begin{abstract}
RESUMO
No debate entre Habermas e Apel a respeito da fundamentação da ética do discurso muitas coisas aparecem misturadas. O artigo reconsidera o debate, analisa a forma do argumento pragmático-transcendental e distingue duas grandes questões em confronto: questões sobre pressuposições argumentativas e questões sobre obrigações morais. Tenta-se mostrar que, feitas as distinções apropriadas, na primeira questão Apel tem mais razão que Habermas, e que, na segunda questão, Habermas tem mais razão que Apel. As implicações de cada posição são consideradas.
\end{abstract}

Palavras-chave: Apel; Habermas, Ética do discurso, Argumento pragmáticotranscendental

\section{ABSTRACT}

In the debate between Habermas and Apel on the foundation of discourse ethics, many things are mixed. The article reconsiders the debate, analyzes the form of the pragmatic-transcendental argument, and distinguishes two major issues in confrontation: questions about argumentative assumptions and questions about moral obligations. We try to show that, having made the appropriate distinctions, in the first question, Apel is more right than Habermas, and that, in the second question, Habermas is more right than Apel. The implications of each position are considered.

Keywords: Apel; Habermas; Discourse Ethics; Transcendental-pragmaticargument

Na década de setenta, na Universidade de Frankfurt, dois filósofos - colegas e amigos - ministraram conjuntamente alguns memoráveis cursos nos quais discutiam muito calorosamente questões ligadas ao que começava a ser chamado de Ética do Discurso [Diskursethik]. A ideia de que a prática coletiva de uma argumentação racional - mesmo aquela levada a cabo pelos cientistas naturais - pressupõe normas que têm conteúdo moral tinha 
sido antecipada no pragmatismo americano - na ideia de Peirce de uma comunidade de pesquisadores que buscam a verdade -, mas foi Apel quem estendeu a comunidade dos pesquisadores para a comunidade de interação dos sujeitos socializados da comunicação cotidiana, abrindo assim a porta para uma nova perspectiva que permitiu pensar em uma "ética do discurso".

Em um longo artigo publicado em dezembro deste ano de 2020, por ocasião de uma homenagem a Apel, Habermas reconhece que sem Apel não teria havido ética do discurso. ${ }^{2}$ Foi Apel quem abriu uma nova dimensão na análise da linguagem e, com isso, completou a "virada linguística":

Ele realizou a transição da semântica formal, que se concentra na estrutura dos enunciados, para a pragmática 'transcendental' da linguagem, centrada nas propriedades formais do uso e da interpretação das expressões linguísticas. Desta forma, ele lançou as bases para uma ética do discurso (HABERMAS, 2020b, 487).

A seguir, Habermas faz uma curiosa observação:

Infelizmente, nas últimas décadas de sua carreira, o próprio Apel deslocou a atenção de seus colegas do tema central da filosofia da linguagem e do caminho em direção à ética do discurso para o tema secundário de sua 'fundamentação última' (HABERMAS, 2020b, 488, [ênfase minha]).

Se a questão da fundamentação da ética do discurso é um "tema secundário", fica pelo menos estranho que Habermas tenha dedicado tanto esforço ao longo dos anos para rejeitar a plausibilidade da fundamentação "última" defendida por Apel. Em minha opinião, o debate em torno do alcance do argumento usado na fundamentação da ética do discurso chamado de argumento "pragmático-transcendental" - foi "inflacionado" por ambos os autores, e a razão é que aparecem misturadas na discussão questões que são muito diferentes: questões sobre argumentos que provariam pressuposições argumentativas e questões sobre argumentos que provariam obrigações morais. Gostaria de reconsiderar, de minha perspectiva, as razões da divergência a respeito da fundamentação da ética do discurso. ${ }^{3}$ Rejeitarei a pretensão de Apel de fundamentar obrigações morais a partir do reconhecimento de pressupostos argumentativos, e argumentarei - contra o que me parece ter sido um pressuposto de Habermas - que não precisamos negar o caráter puramente conceitual ou 
lógico do argumento pragmático-transcendental para negar que este possa fundamentar obrigações morais.

\section{O ponto de partida}

A ética do discurso recebe este nome pelo fato de ser uma teoria moral que tenta fundamentar um princípio moral nas argumentações. A ideia de que a prática da argumentação racional pressupõe normas que têm conteúdo moral não é tão estranha assim. Tal prática coletiva de troca de argumentos implica a aceitação de múltiplos compromissos: respeitar as regras lógicas, dizer a verdade, fornecer razões para as afirmações que fazemos e dar atenção a todas as objeções que nos sejam feitas. A busca cooperativa da verdade, ou da correção de nossas pretensões ligadas a normas, precisa se apoiar em certas idealizações da situação epistémica que envolvem o reconhecimento de todos os participantes enquanto interlocutores com os mesmos direitos. Trata-se de "pressuposições inevitáveis". As controvérsias começam na hora de interpretar qual a força de tais "pressuposições inevitáveis" de conteúdo normativo desvendadas por meio do argumento pragmático-transcendental (a seguir: APT). Quais implicações se seguem do reconhecimento dessas regras "morais" dentro das argumentações para o agir social fora das argumentações? Conduzem as pesquisas sobre a Ética do Discurso a uma ética substantiva que coloca para nós obrigações morais enquanto argumentadores racionais, e especialmente enquanto filósofas ou filósofos? Ou se trata de uma teoria da moral sem pretensões de guiar diretamente a conduta?

\section{O debate Habermas vs. Apel: duas questões em confronto que aparecem misturadas}

Na minha opinião, no debate entre Apel e Habermas sobre a ética do discurso há duas grandes questões em confronto, e é muito importante distingui-las: (I) A primeira constitui um problema da razão teórica. O que se discute é se o APT é um tipo de argumento transcendental "bemsucedido"; isto é, se é capaz de estabelecer pressupostos de forma conceitual ou lógica, ou se, quando muito, é apenas um mecanismo heurístico proveitoso para formular hipóteses linguísticas muito gerais. (II) A segunda questão está ligada à razão prática. A tentativa de fundamentar regras que tenham autêntico conteúdo "moral" enquanto pressupostos necessários das argumentações tem que provar uma conexão necessária entre os discursos e as ações: Mesmo que a prova do reconhecimento necessário de regras de conteúdo moral na argumentação fosse bemsucedida, o que deve ser mostrado é que aquelas regras necessariamente 
reconhecidas pelos que argumentam, no momento que argumentam, têm validade para o agir fora das argumentações. Eu creio que, feitas as distinções apropriadas, na primeira questão Apel tem mais razão que Habermas, e que, na segunda questão, Habermas tem mais razão que Apel.

Trata-se de duas questões bem diferentes. Acontece que aparecem misturadas na discussão. Apel crê que o APT auto-fundamenta a razão teórica e a razão prática em um ponto único, então, para ele, provar a primeira questão é também provar a segunda. Mas podemos interpretar o APT como um tipo de argumento conceitual ou lógico (i. e., não empírico), no sentido em que foi compreendido em geral na longa discussão sobre transcendental arguments na filosofia anglo-saxã contemporânea, e não admitir que ele possa provar tudo o que Apel acredita que prova. O APT, mesmo interpretado como uma prova conceitual, portanto a priori, estabeleceria apenas regras ou pressupostos argumentativos, não normas morais. Não precisamos negar o caráter "transcendental" do argumento para negar que por meio dele possamos fundamentar obrigações morais.

Assim, creio que a estratégia de fundamentar uma ética por meio do APT, no sentido pretendido por Apel de fundamentar uma obrigação moral a um cético meta-ético, não pode escapar ao dilema discurso teóricodiscurso prático/moral: não parece difícil provar normas de reconhecimento recíproco como pressupostos necessários do discurso teórico, mas não se vê por que poderiam aspirar a ter validade fora das relações estritamente discursivas, i. e., não teriam autêntica validade moral; e se se tentasse prova-las como pressupostos do discurso moral (talvez junto com algum outro suposto) poderia se obter delas um principio de relevância moral semelhante a $U$, mas este só teria validade para quem participa dos discursos morais, não precisamente para os céticos meta-éticos.

Dividirei a exposição em duas partes, correspondentes às duas grandes questões que distingo no debate.

Na parte final, refletirei sobre o que creio ser a verdadeira motivação para a bifurcação dos caminhos teóricos de ambos os autores após o debate sobre o alcance do APT.

\section{O argumento pragmático transcendental}

\section{Kant, os transcendental arguments e Aristóteles}

Foi Apel quem desenhou o famoso argumento pragmáticotranscendental. Trata-se de um tipo argumento anti-cético, de uma prova 
"indireta", não dedutiva, que procura justificar pressuposições linguísticas mostrando-as como condições necessárias do uso da linguagem. O argumento está dirigido a um cético que tenta negar essas pressuposições. Apesar do adjetivo "transcendental" se referir à filosofia kantiana, o argumento desenhado por Apel, como veremos, tem muita mais afinidade com a defesa aristotélica do princípio de não contradição do que com a argumentação transcendental kantiana.

Para Kant, os princípios transcendentais possuem um status especial com relação ao conhecimento em geral, pois exprimem as condições que têm que ser satisfeitas para que qualquer conhecimento empírico seja possível. Estas proposições transcendentais são, para Kant, juízos sintéticos a priori: pretendem enunciar verdades a priori (universais e necessárias) que não são meramente conceituais (analíticas), mas verdades sobre objetos (como as outras proposições sintéticas). Elas não podem ser fundamentadas nem empiricamente, nem só por meio da análise de conceitos, mas exigem um tipo de prova especial que chama de "dedução transcendental". Não é fácil delimitar que foi exatamente para Kant uma dedução transcendental. Os argumentos de Kant estão tão entremeados com conceitos próprios da sua filosofia que se torna difícil separar uma forma típica do que seria uma prova transcendental.

Após a proposta de reconstrução "austera" da argumentação kantiana, realizada por Strawson (1966), produziu-se uma avalanche de artigos sobre transcendental arguments na filosofia anglo-saxã (STROUD, 1968; WALKER, 1989; HACKER, 1972; HARRISON, 1989). Poderíamos caracterizar o argumento transcendental "pós-kantiano" como um tipo de prova indireta, um argumento anticético que tenta reconstruir a argumentação kantiana despida de seus pressupostos idealistas. De maneira geral, o argumento se constrói considerando uma alternativa para a posição cética e demonstrando a incoerência interna dessa alternativa. Nos polos extremos do debate temos, de um lado, aqueles que consideram que pode haver argumentos transcendentais válidos capazes de estabelecer conclusões sintéticas e a priori (FÖRSTER, 1989) e, de outro lado, aqueles que os consideram meros argumentos "de parasitismo", pois a única coisa que poderiam pretender é mostrar a um cético que as noções que ele utiliza são parasitárias de noções convencionais mais fundamentais (RORTY, 1971). Na esteira de Kant, a maior parte dos argumentos discutidos neste corpus tenta provar condições de possibilidade de nosso conhecimento do mundo externo contra um cético que admite ter experiências subjetivas, mas nega o nexo necessário delas com o mundo externo. Poucos focam em pressupostos do uso da linguagem. 
O argumento transcendental de tipo pragmático desenhado por Apel é mais parecido com a defesa aristotélica do princípio de não-contradição, que está dirigida contra um cético que duvida de uma regra da linguagem: nada menos que do princípio de não-contradição. Contra ele, Aristóteles articula uma autêntica refutação transcendental. Como é obvio, o princípio não pode ser demonstrado dedutivamente sem incorrer em petição de princípio, porque é um pressuposto de toda e qualquer demonstração. A estratégia do argumento usado por Aristóteles consiste em substituir a demonstração impossível por uma refutação: fazer valer o fato de que o próprio oponente cético, que quer negar o princípio, o pressupõe desde sempre (MET. IV 4 1006a5-b34).

Note-se que para provar "o mais certo dos princípios", Aristóteles não pode neste caso, como acontece geralmente nos diálogos socráticos, pôr em evidência uma contradição lógica na tese de do oponente, porque este é um cético muito radical, que coloca em dúvida o próprio princípio de não contradição.

O ponto de partida do argumento é algo que o cético não pode recusar. Aristóteles pede tão-somente para o seu interlocutor cético que enuncie uma expressão linguística que possua um significado público: "que signifique algo para ele mesmo e para outro". Então, poderá lhe mostrar que ele pressupõe de antemão o princípio. O princípio enuncia uma condição necessária de toda linguagem significativa. Se não for aceito, não há linguagem possível. A prova parece tão contundente porque parte de um requisito mínimo que o interlocutor cético não poderia rejeitar. Tal como Aristóteles desenha a prova, a única opção que resta ao cético é se refugiar no silêncio permanente. Mas um cético que não fala não é sequer um cético: "tal homem não seria mais que um vegetal", diz Aristóteles. Se abandonar a linguagem, sequer pode questionar o princípio. Se, em contrapartida, se comunica com os outros, o argumento parece atingi-lo.

A prova mostra, em resumo, que:

- o princípio é um pressuposto inevitável, que é preciso aceitá-lo (explicitamente) porque já o aceitamos (implicitamente) toda vez que falamos.

- só existem duas alternativas: ou bem o cético renuncia à linguagem, ou bem fala significativamente e, então, aceita as regras do discurso.

A maior parte das questões em confronto no debate entre Apel e Habermas sobre o alcance do APT está cifrada nesta cena aristotélica. Uma questão muito discutida é a de se o APT pode excluir que existam outras alternativas para os pressupostos argumentativos provados por meio do 
argumento. Será que há mesmo apenas duas alternativas: ou ser membro pleno da comunidade dos falantes ou ser mera planta? ${ }^{4}$

Para aquele que quer provar o princípio, obviamente, só existem duas alternativas. Trata-se de duas possibilidades lógicas que decorrem da tentativa de negar o princípio proposto. Parece "inevitável", para quem quer provar o princípio, supor um cético racional e consequente como interlocutor de seu argumento - tão consequente que seria capaz de deixar de falar para sempre somente para "cumprir sua palavra". Mas é claro que para o cético, ou melhor, para um cético real, sempre existe uma terceira possibilidade: falar de modo significativo, mas sem se comprometer explicitamente com a aceitação de nenhum dos princípios ou regras implicados no discurso. Não interessa quão contundente possa ser a prova, o cético sempre pode continuar a fazer uso da linguagem. O cético também pode argumentar, ou pelo menos tentar fazê-lo. E, geralmente, é o que os céticos fazem. O cético sempre pode aduzir que falar com sentido não o constrange a aceitar nenhum princípio ou regra "inevitável". Para quem quer provar o princípio, sem dúvida, este é um cético bastante "mau": alguém que ousa mostrar com sua conduta que as plantas podem falar. A possibilidade deste tipo de conduta de parte do cético parece complicar as coisas no debate entre Apel e Habermas, porque não se sabe muito bem se há que considerá-la ou não no argumento. Um argumento deste tipo deixaria de ser conclusivo face à possibilidade de ser rejeitado por este cético "mau"? Tudo parece depender de que tipo de pressupostos o argumento pretenda provar, se regras argumentativas ou obrigações morais. Por isso a importância de distinguir as duas questões de debate apontadas acima.

É verdade que eficácia deste tipo de argumentos depende bastante do que o cético esteja disposto a aceitar. Contudo, algo parecido acontece com qualquer argumento. Se o cético não aceitar pelo menos o modus ponens, não se poderá provar nada para ele, uma vez que ele nunca iria aceitar que as premissas de um argumento possam implicar a conclusão. Não há argumento que atinja um cético totalmente irracional, pois os seus movimentos seriam imprevisíveis. No entanto, não deveríamos supor um cético irracional como interlocutor de nenhum argumento. A eficácia ad hoc de um argumento nada tem a ver com sua validade. A validade de um argumento de prova de pressupostos argumentativos não depende de sua efetiva aceitação pelos céticos. No caso de um argumento desenhado para convencer um cético determinado, importa partir daquilo de que o cético não duvida: daquilo sobre o qual ele constrói sua dúvida. Por isso, é importante caracterizar de modo adequado o cético de cada argumento 
transcendental. Vejamos agora como Apel constrói sua prova face ao seu oponente cético.

Apel inventou o APT - e lhe deu o viés pragmático, não-dedutivo, que o caracteriza - em seu debate contra o racionalismo crítico, a perspectiva teórica que sustenta justamente a impossibilidade de fundamentar princípios "últimos" baseando-se na impossibilidade demonstrá-los de modo dedutivo. Albert, o representante do racionalismo crítico com quem Apel debate, apresentou o problema na forma de um trilema (chamado "de Münchhausen"). Dado que a dedução só serve para explicitar aquilo já foi pressuposto como válido, toda e qualquer tentativa de fundamentar princípios últimos conduz a um trilema: ou bem um regresso ao infinito, ou bem a um círculo lógico, ou bem ao estabelecimento de determinados princípios como axiomas não justificados. Baseando-se no trilema de Münchhausen, o racionalismo crítico sustenta a impossibilidade em geral de se fundamentar princípios de modo não-dogmático. De acordo com isto, sustenta um princípio falibilista - ou de crítica ilimitada - , segundo o qual todos os enunciados devem ser considerados como sendo hipóteses falíveis. Não pretende fundamentar tal princípio, porque isso demonstrou ser impossível. Aconselha, em contrapartida, tomar uma decisão a favor dele; uma decisão que não é racional, mas moral (ALBERT, 1968).

Apel quer defender a existência de princípios induvitáveis, "últimos", porque seriam pressupostos ou condições de possibilidade de outros enunciados. Qualquer tentativa de demonstração dedutiva incorreria em uma petição de princípio, porque os princípios estariam pressupostos por qualquer demonstração. A estratégia de Apel consiste em provar que o oponente que nega isso se autocontradiz. O que mostra, contra Albert, é que a tese falibilista não pode ser afirmada sem contradição, pois ela incorre num paradoxo semelhante ao do mentiroso: ao se tratar de um enunciado que enuncia uma condição para todos os enunciados, resulta paradoxal quando se aplica essa condição a si mesmo. Se o enunciado que enuncia o princípio do falibilismo ("Todos os enunciados são falíveis") é ele mesmo uma hipótese falível, então não contradiz verdadeiramente a tese de que pode haver enunciados "não-falíveis", motivo pelo qual se contradiria. E se o enunciado do princípio do falibilismo não é uma hipótese, se deve ser afirmado como válido a priori, então é falso, porque ele mesmo afirma que todos os enunciados são hipóteses (APEL, 1976).

Conclusão: O enunciado do princípio do falibilismo deve ser corrigido por ser paradoxal. A afirmação de que todos os enunciados devem ser considerados falíveis não pode ser aplicada ao próprio enunciado que afirma essa prescrição. Para conservar o sentido que a tese falibilista pretende, a possibilidade de que todos os enunciados sejam submetidos à crítica deve 
ser afirmada como sendo válida a priori; de outra maneira sequer pode haver "falibilismo". O princípio do falibilismo só pode ter sentido e validade se for restringido de tal modo que ele mesmo fique excluído da crítica.

\section{A contradição performativa}

Note-se a forma do argumento anticético usado por Apel contra o racionalismo crítico: O proponente não somente aceita o ponto de partida do oponente, mas se apropria da mesma forma de objeção cética para sustentar precisamente o contrário. Aí onde o oponente vê impossibilidade, o proponente quer mostrar necessidade: a possibilidade da dúvida cética se funda na necessidade de aceitar o princípio proposto. Do debate com Albert, Apel extrai a fórmula da prova "pramático-transcendental":

Se eu não posso contestar algo sem autocontradição atual e nem, ao mesmo tempo, fundá-lo dedutivamente sem petição de princípio lógico-formal, então isto pertence precisamente àqueles pressupostos pragmático-transcendentais da argumentação que é preciso haver reconhecido sempre, caso o jogo de linguagem da argumentação deva conservar seu sentido (APEL, 1976, 166).

Esta autocontradição "atual" é a que ficou depois conhecida como autocontradição "performativa". Em formulações posteriores fica mais claro o caráter dialógico da prova. Pressupostos invitáveis são "Todos os pressupostos da argumentação que cumprem a condição de que não podem ser negados por nenhum oponente sem autocontradição atual e que não podem ser demonstrados sem petitio principii [...]". (APEL, 1980, 154 [ênfase minha]). A contradição que se procura produzir no oponente é uma contradição performativa.

Depois, Apel estende esta forma da prova de pressupostos a outros elementos da situação argumentativa. A prova requer algumas sondagens. Ela não permite gerar automaticamente princípios. É preciso propor enunciados "candidatos a inevitáveis". É preciso imaginar objeções céticas para cada regra ou pressuposto candidato a inevitável e comprovar se não se produz uma autocontradição performativa ao tentar negá-los. A prova estende-se assim a todos aqueles pressupostos argumentativos que não podem ser negados por um oponente sem que se produza uma contradição entre o que se afirma e o ato de afirmar.

Assim, usando esta fórmula da autocontradição performativa, Apel extrai um sistema de regras ou de pressupostos inevitáveis dos atos de fala argumentativos: (a) as regras de uma lógica mínima (ou seja, os 
princípios da lógica formal); (b) determinados pressupostos de existência, tais como a existência da linguagem e dos sujeitos que argumentam; (c) as regras que regulam a interação dos que argumentam enquanto falantes, ou seja, as quatro pretensões de validade que tinham sido formuladas inicialmente por Habermas. Um cético que afirmasse que não tem nenhuma pretensão de inteligibilidade, de veracidade, de verdade, ou de correção normativa para seus proferimentos estaria contradizendo performativamente sua própria ação linguística. Assim, por exemplo, o falante não pode dizer (sem se autocontradizer) "Afirmo $p$ mas não creio que $p$; minto". Este é o paradoxo do mentiroso. O falante não pode negar perante o ouvinte sua própria pretensão de veracidade.

Neste ponto parece controversa a pretensão de Apel de que os enunciados que expressam pressuposições inevitáveis não são analíticos (1984: 21). Apel parece pensar num tipo de relação necessária que não é dedutiva, mas reflexiva, e com isso apelar para certa evidência "de consciência". Apel pensa a linguagem natural como uma metalinguagem última que já não pode ser objetivada. A contradição performativa seria uma contradição entre o afirmado num ato linguístico e um "saber do agir" de tipo reflexivo implícito na realização desse ato. ${ }^{5} \mathrm{Eu}$ entendo que a contradição performativa não é outra coisa que uma contradição lógica entre duas proposições. A contradição lógica se torna evidente quando o proponente faz lembrar ao cético o que ele está fazendo pragmaticamente. Na hora de "prová-la" a um oponente aquilo que é compreendido numa atitude performativa é traduzido naquilo que pode ser constatado do ponto de vista de uma terceira pessoa. Naturalmente, o cético sempre pode não aceitar que esteja cometendo uma contradição. O que o argumento mostra é a impossibilidade de recusar determinadas regras. Qual o status desse tipo de argumentação?

\section{As objeções de Habermas}

Como é sabido, Habermas questiona a pretensão de que o APT possa ser considerado como uma prova a priori à luz de sua concepção de "ciência reconstrutiva", um tipo de ciência que estaria a meio caminho entre as ciências empírico-analíticas e as ciências hermenêuticas, a qual só poderia oferecer fundamentações transcendentais "fracas" ou "quasetranscendentais". Não vou entrar na questão do status epistemológico que deveria ser atribuído a esse tipo de saber. Parece-me que a recusa de parte de Habermas da pretensão de Apel de fundamentar obrigações morais a partir do APT, com a qual estou de acordo, independe dessa questão. 
Mesmo que o APT fosse bem sucedido em provar pressupostos argumentativos de forma a priori, deles não poderíamos derivar obrigações morais, como pretende Apel.

Contudo, se a reconstrução do argumento de Apel que realizei acima é correta, o APT tem que ser entendido como argumento de tipo puramente conceitual, não empírico. Se esse é o caso, a pretensão de Habermas de que a afirmação de que não existem alternativas para os pressupostos candidatos a inevitáveis "tem que ser verificada sobre a base de casos, do mesmo modo que qualquer hipótese de uma lei" (HABERMAS, 1989, 120) não se sustenta. Se o que se pretende é desvendar regras que reproduzam corretamente intuições de falantes, e se o critério para as estabelecer é a consulta aos falantes competentes, as regras assim reconstruídas nunca poderão ser interpretadas como condições necessárias. ${ }^{6}$ Não parece fazer sentido mostrar que um pressuposto é uma condição necessária (impossível de ser negada sem contradição) e esperar que algum dia possa vir a ser refutado pelos fatos: estaria se afirmando simultaneamente sua "inevitabilidade" e sua "não-inevitabilidade". Da mesma forma, parece não fazer sentido esperar que uma reconstrução empírica de regras pudesse algum dia prová-las como condições necessárias. Entendo que considerar o APT como um argumento que estabelece regras argumentativas de maneira conceitual não impede que outras tarefas reconstrutivas possam vir a ser realizadas a respeito das normas morais, especialmente enquanto processos de aprendizagem histórica. ${ }^{7}$ Essa tarefa é levada a cabo por Habermas em seu último livro (2019).

A reconstrução de regras realizada pelo APT é "falível", mas não no sentido de poder ser refutada pelos fatos. É falível porque qualquer um pode se equivocar, mas o único modo de recusá-la é mostrando sua inconsistência lógica: se os pressupostos "candidatos a inevitáveis" são aqueles "que não podem ser negados sem contradição", o único modo de refutá-los é mostrar que eles "podem ser negados sem contradição".

Uma outra objeção apresentada por Habermas, que já aparecia de forma recorrente no debate sobre os argumentos transcendentais na filosofia anglo-saxã, é a objeção de que o APT apenas provaria a impossibilidade de recusar determinados pressupostos e que, por isso, a prova não pode excluir que outras alternativas possam ser válidas. Desde a resposta dada por Eva Schaper, a réplica a esta objeção é que o argumento coloca só duas alternativas contraditórias (KÖRNER, 1967; SCHAPER, 1972). Segundo tentamos mostrar, para provar que uma condição determinada é "inevitável", o APT procede considerando uma alternativa, mas não qualquer alternativa: só a negação da condição. E esta anula o campo de possíveis alternativas a esta condição (PH. GRIFFITHS, 
1975; FÖRSTER, 1989; HARRISON, 1989). Trata-se de duas alternativas contraditórias - e não simplesmente contrárias. Se alguém acreditar que existem outras alternativas, deve tentar prová-las como condições necessárias. A prova pretende mostrar, justamente, a impossibilidade de negar os pressupostos "inevitáveis".

Em resumo: O APT é um tipo de argumento conceitual. Dado que é uma prova dialógica indireta, o argumento precisa começar com um cético que negue a proposição que para o/a filósofo/a transcendental é um pressuposto inevitável. A seguir o/a filósofo/a transcendental lhe mostra que está se contradizendo com uma implicação do seu proferimento: "Se $A$ então B". O argumento coloca duas alternativas: ou bem o cético aceita o pressuposto em questão, ou bem não argumenta com sentido. Se não há razões lógicas que mostrem a inconsistência desta afirmação do proponente, isto é, se de fato esse pressuposto "candidato a inevitável" não pode ser negado sem contradição, então, o pressuposto inevitável estaria provado. O cético teria que aceitar a afirmação do proponente como uma implicação inevitável daquilo que já aceitou como justificado. Obviamente, o cético sempre poderá negar que $B$ se segue de $A$, por mais que para o filósofo transcendental esta ligação pareça de uma claridade meridiana. De um modo geral, em qualquer argumento deste tipo efetivamente oferecido, a discussão se emperra neste ponto, e isso pode ser muito desmotivador. Porém, caso o cético continue participando da argumentação, só lhe resta a possibilidade de contra-argumentar: tentar provar que $A$ é possível sem pressupor B.

A importante questão que deve ser esclarecida neste debate é se podemos pretender fundamentar algo a mais do que obrigações argumentativas por meio do APT, i. e. obrigações morais categóricas. De fato, o principal motivo pelo qual Habermas recusa a forma de fundamentação transcendental tem a ver com a pretensão de fundamentar uma ética por esta via. E nesse ponto as suas razões parecem muito mais convincentes.

\section{II \\ A teoria moral}

Então, independentemente do status a priori ou empírico dos pressupostos "inevitáveis" de conteúdo normativo das argumentações racionais, a questão que deve ser respondida é Por que as regras que regem a cooperação entre filósofos ou cientistas poderiam pretender regular o agir também fora das argumentações? E, em primeiro lugar, o que deve ser esclarecido é Qual a relação que existe entre as regras "de conteúdo moral" 
que regulam a argumentação e as normas propriamente morais, que regulam as ações fora das argumentações? Note-se que, a respeito desta última questão, a resposta de Apel e de Habermas é a mesma: Ambos pensam que nas primeiras (nas regras argumentativas) está suposto o critério para justificar as segundas (as normas propriamente morais). Este é o cerne da ética do discurso. Contudo, Apel e Habermas seguem caminhos opostos. A prova da conexão necessária entre ações e discurso é realizada por Apel a partir do discurso (de cima para baixo) e, por Habermas, a partir das ações (de baixo para cima). E o significado dado por cada um deles à prova da conexão entre discursos e ações será radicalmente diferente. Para Apel, a filosofia fundamenta a moral; para Habermas, a filosofia fundamenta uma teoria (falível) das justificações morais.

O caminho de Apel é intricado, altamente especulativo, e também mais breve. É um caminho "de cima para baixo". Apel pretende, em um mesmo movimento, provar o princípio da ética do discurso como um pressuposto inevitável das argumentações e como uma norma moral obrigatória, válida para todo falante - como uma norma que exige aos falantes a realização de discursos em cada conflito de relevância prática na práxis vital. Só no discurso - por meio do APT - poderiam ser provadas a necessidade teórica e a necessidade prática de aceitar o que ele chama de "norma ética fundamental". 8

Mas é possível fundamentar - no mesmo ato - a necessidade prática de reconhecer pressupostos que se revelam como necessários só teoricamente? Vale lembrar o dilema discurso teórico - discurso prático que mencionamos acima. Se o cético moral do APT é alguém que sustenta que as normas não são passíveis de justificação discursiva, não podemos pretender provar para ele as regras "morais" da argumentação como pressuposições do discurso moral, isto é, como pressuposições de uma forma de discurso em que já se subentende que as normas morais poderiam ser justificadas. Este cético meta-ético não participa de discursos morais. Ao contrário, participa de um discurso teórico, e pede razões (teóricas) para participar de discursos morais.

O que Habermas coloca em questão é a pretensão de se obter normas morais - válidas para o agir - diretamente a partir de pressupostos inevitáveis das argumentações. Por meio do APT podemos provar apenas regras inevitáveis das argumentações. E as regras que são inevitáveis dentro dos discursos não podem - imediatamente - pretender ter validade fora do âmbito das relações estritamente discursivas, pois o discurso está, justamente, "libertado da pressão do agir". O lugar da moral não é primariamente - o diálogo argumentativo, mas a vida cotidiana. As obrigações morais, e as questões a respeito da validade de ações e normas, 
são questões da vida cotidiana; elas aparecem antes de qualquer forma de reflexão filosófica. Só se mostrarmos que o discurso está embutido na estrutura do agir teleológico mediado pela linguagem poderemos pretender mostrar, depois, que as normas podem ser justificadas discursivamente. Ao final, as relações de reconhecimento recíproco que têm que ser supostas no discurso são pressupostos pragmáticos que o discurso - enquanto forma refletida de comunicação - "toma de empréstimo" ao agir comunicativo.

Por isso o caminho de Habermas é um caminho "de baixo para cima". Nele a teoria do agir comunicativo desempenha um papel central. O ponto de partida é uma teoria do agir social e o ponto de chegada, uma teoria da argumentação moral. A primeira tarefa é mostrar que o agir social não é apropriadamente concebido como uma interação estratégica, mas como um agir orientado por pretensões de validade, ou seja, que as pretensões de validade normativas estão implícitas nas ações sociais e necessariamente apontam para uma resolução discursiva; depois, o argumento pragmáticotranscendental pode "provar" "U" como uma regra da argumentação dos discursos práticos. ${ }^{9}$ Mas não pode prová-lo apenas pressupondo regras argumentativas. É necessário que o oponente do argumento já tenha sido socializado, saiba o que significa ter obrigações morais, e possa vincular esse saber às obrigações argumentativas. Apenas se essas condições estão dadas, ao participar em um discurso moral, poderá aceitar a exigência de considerar imparcialmente os interesses de todos e poderá adotar uma atitude autocrítica com respeito a seus próprios interesses. Mas a força da obrigação moral provém das normas que são introduzidas nos discursos prático-morais pelo fato de ter se tornado problemáticas. O dever moral está, para Habermas, nas normas moralmente vinculantes que operam como mecanismo para coordenar as interações no mundo da vida. São essas normas sociais que podemos examinar criticamente do ponto de vista moral nos discursos prático-morais, discursos estes que, na concepção de Habermas posterior a Facticidade e Validade, após a revisão da arquitetura da teoria, devem ser estritamente distinguidos de outros tipos de discursos práticos, e muito especialmente dos discursos jurídicos.

Em conclusão, e voltando para a importância de distinguir as duas grandes questões do debate que coloquei no início, o problema central do debate entre Habermas e Apel sobre a ética do discurso não é se o APT é um argumento conceitual ou empírico, o problema central é se, em condições pós-metafísicas, qualquer argumento, seja conceitual, seja empírico, pode fundamentar obrigações morais categóricas. Nesse ponto, entendo que Habermas tem razão: a resposta é negativa. 
O debate entre os dois filósofos com respeito à fundamentação da ética do discurso perpassou diferentes etapas. A época do maior acordo começou a se desmanchar justamente na hora de tentar determinar o alcance do APT. Parece-me, contudo, que a motivação mais importante para a bifurcação dos caminhos empreendida por Habermas tem a ver com um problema já não podia ser mantido naquele momento como telão de fundo, e que exigia confirmar ou redefinir a "arquitetura" das teorias, qual seja: dar conta de maneira adequada da relação da moral com o direito.

Parece-me que foi Albrecht Wellmer quem melhor exprimiu esse problema:

A ligação do direito com a moral no princípio $U$ consegue-se ao preço de uma assimilação conceitual dos problemas morais aos problemas jurídicos. No princípio $U$ "misturam-se" um princípio moral universalista com um princípio de legitimidade democrática, e o fazem de uma maneira tão confusa que ao final de contas não fica convincente nem como princípio moral nem como princípio de legitimidade (WELLMER, 1986, 154).

Em 1992 Habermas publica Facticidade e Validade, livro no qual redefine a arquitetura da teoria. O princípio moral de universalização já não aparece no topo da construção teórica, e não pretende já ser também um princípio de legitimidade. O princípio do discurso (D) exprime a ideia de imparcialidade nos juízos práticos, mas de uma maneira neutral, ainda indiferente à distinção entre moral e direito. Ele tem que ser especificado em cada caso para que possa servir de critério de correção, respectivamente, das normas morais ou das normas jurídicas: no primeiro caso, adota a forma do princípio moral de universalização $U$; no segundo, adota a forma do princípio da democracia. Evita-se assim uma implausível subordinação iusnaturalista do direito à moral, algo que se segue da posição de Apel.

Habermas não apenas quer evitar a subordinação iusnaturalista do direito à moral, mas também recusar a tese positivista da separação completa entre direito e moral. Uma compreensão adequada das condições da vida social no estado moderno exigiria levar a sério a separação entre moral e direito como diferentes domínios de normas de ação, mas ao mesmo tempo dar conta da relação que existe entre ambos os domínios. Não parece tão clara, contudo, ao menos para mim, a tese da "complementariedade" entre direito e moral que passou a defender a partir de então, especialmente a concepção da moral que parece ali pressuposta. A Ética do discurso, como Wellmer também apontou, tem uma concepção "normativista" da justificação moral. Nela se pressupõe que nas 
controvérsias morais cotidianas as pessoas discutimos primariamente sobre a validade de normas, e não sobre a validade de maneiras de agir na situação, à luz de normas. É essa concepção da moral que parece ainda menos plausível na nova configuração defendida por Habermas.

\section{Notas}

1 Professora Associada da Universidade Federal do Rio de Janeiro. E-mail: marina.isa.velasco@gmail.com

2 Ver nessa mesma edição da revista Ethic@ o artigo de Habermas: Da semântica formal à pragmática transcendental: a ideia original de Karl-Otto Apel (2020, 587517).

${ }^{3}$ Abordei o tema no livro: Ética do Discurso: Apel ou Habermas? (2011).

${ }^{4}$ Barbara Cassin (1990) identifica neste modelo argumentativo a origem de toda exclusão totalitária do insensato: o "outro", que fala sem sentido, é reduzido ao "nada".

${ }^{5}$ Apel insiste em postular um tipo de evidência de consciência - "fenomenológica" - que não parece ser muito compatível com a pretensão simultânea de se manter num nível meramente linguístico. Cf. especialmente 1987: 92 n60, em que qualifica os juízos reflexivos ao respeito do saber performativo do agir como "juízos perceptivos não sensíveis". Às vezes tem-se a impressão de que é sua insistência em interpretar a contradição performativa também enquanto evidência de consciência o que o leva a enfatizar o caráter moral dos pressupostos argumentativos. Neste ponto, a objeção de Habermas, agora reiterada no artigo de 2020, é acertada: Apel parece chamar a atenção para a identificação reflexiva de uma operação realizada previamente e modo intuitivo "tão-somente sob as condições da filosofia da consciência". Isso estaria vedado no momento em que nos movêssemos no plano analítico da pragmática da linguagem (HABERMAS, $1983,119)$.

${ }^{6}$ Apel não nega que a individualização dos pressupostos "candidatos a inevitáveis" exija investigações sobre os argumentantes empíricos, porém estas investigações teriam um valor meramente heurístico (APEL, 1987, 121), pois aquilo que ele se propõe levar a cabo não é uma teoria descritiva, que pode ser mais ou menos adequada aos fatos que quer descrever - e, por isso, "empiricamente falível" -, e sim uma análise dos pressupostos "inevitáveis" da argumentação no sentido lógico de ser impossíveis de ser negados sem contradição.

7 No arcabouço teórico de Habermas, a pragmática formal é a principal ciência reconstrutiva. Ela reconstrói de maneira horizontal o sistema de regras que possibilita o acordo entre sujeitos socializados linguisticamente. Essa tarefa não impede, contudo, que um outro tipo de reconstrução vertical possa ser realizada, que considere a evolução de estruturas normativas em processos de aprendizagem (Nobre \& Repa, 2012, 26). 
${ }^{8}$ Apel não faz a distinção entre o princípio "U" - entendido como uma regra dos discursos práticos - e o princípio "D" - entendido como a proposta de uma teoria moral entre outras, segundo o entendimento de Habermas prévio a Facticidade e Validez. O que Apel chama de "norma ética fundamental", em seus primeiros artigos (1973, por exemplo), ou "o princípio do discurso", em textos posteriores (1989), inclui essas duas instâncias: "U" e "D". Ao final, "D" seria o momento "prescritivo" da pressuposição argumentativa (APEL, 1989, 35).

${ }^{9}$ Habermas (1980, 444; 1983, 79 ss., 111, 122, 161-2, 138 n 64). Os passos são os seguintes: (I) A investigação tem como ponto de partida uma análise de tipos de ações sociais (teoria da ação) na qual se mostra que o agir social não pode ser concebido como uma interação estratégica, mas como uma ação orientada para o entendimento, ou comunicativa, em que os atores se orientam por pretensões de validade ligadas aos atos de fala. Este passo depende, por sua vez, de uma análise do uso comunicativo da linguagem (tese do parasitismo). (II) A pragmática universal (ou "teoria do significado pragmático-formal") desempenha esta última tarefa: explica o significado das pretensões de validade normativas (em analogia com as pretensões de verdade), apelando para seu resgate ou resolução discursiva. (III) Chega-se assim à teoria da argumentação moral - ou lógica do discurso prático. Neste contexto, postula-se o princípio de universalização ("U"), entendido como uma regra da argumentação que permite chegar a um acordo nos discursos práticos. (IV) O passo seguinte é a prova de "U". É neste ponto - e só neste ponto - que Habermas reconhece usar o APT. 


\section{Referências Bibliográficas}

ALBERT, Hans. (1968) Traktat über kritische Vernunft, Tübingen: Möhr.

APEL, Karl-Otto. (1976) "Das Problem der philosophischen Letzbegründung im Lichte einer transzendentales Sprachpragmatik: Versuch einer Metakritik des 'Kritischen Rationalismus'". In: B. Kanitscheider (ed.), Sprache und Erkenntnis, Innsbruck, pp. 55-82. (Trad. esp.: "El problema de la fundamentación última filosófica a la luz de una Pragmática Trascendental del Lenguaje (Ensayo de una metacrítica del 'racionalismo crítico')". In: Dianoia, XXI 21 (1975) 140-173).

APEL, Karl-Otto. (1980) "Notwendigkeit, Schwierigkeit und Möglichkeit einer philosophischen Begründung der Ethik im Zeitalter der Wissenschaft". In: P. Kanellopoulos (ed.), Festschrift für K. Tsatsos, Athen, pp. 215-75. (Trad. esp., em Estudios Eticos, Barcelona, Alfa, 1986, 105-173).

APEL, Karl-Otto. (1984) "Das Problem einer philosophischen Theorie der Rationalitätstypen". In: H. Schnädelbach (ed.), Rationalität, Frankfurt, pp. 5-31. (Trad. esp., em Estudios Éticos, Barcelona, Alfa, 1986, 9-26).

APEL, Karl-Otto. (1987) "Fallibilismus, Konsenstheorie der Wahrheit und Letztbegründung", em Philosophie und Begründung, Frankfurt, Suhrkamp. (Trad. esp. "Falibilismo, teoría consensual de la verdad y fundamentación última". In: Teoría de la verdad y ética del discurso, Barcelona, Paidós/I.C.E.-U.A.B., 1991).

APEL, Karl-Otto. (1989) "Normative Begründung der 'Kritischen Theorie' durch Rekurs auf lebensweltliche Sittlichkeit? Ein transzendentalpragmatisch orientierter Versuch, mit Habermas gegen Habermas zu denken". In: Zwischenbetrachtungen im Prozess der Aufklärung, J. Habermas zum 60 Geburtstag, hrsg.v. A. Honnet, Th. McCarthy, Cl. Offe u. A. Wellmer, Frankfurt, Suhrkamp Verlag.

ARISTÓTELES, Metafísica.

CASSIN, Barbara. (1990) "Fala se tu és um homem" em Ensaios Sofísticos. São Paulo: Siciliano.

FÖRSTER, Eckart. (1989) "How are Transcendental Arguments Possible?". In: E. 1989 Schaper and W. Vossenkuhl (eds.), Reading Kant, NY/Oxford, Basil Blackwell, pp. 3-20.

HABERMAS, Jürgen. (1983) Moralbewusstein und Kommunikatives Handeln, Frankfurt, Suhrkamp. (Trad. port., Consciência moral e agir comunicativo, Rio de Janeiro, Tempo Brasileiro, 1989). 
HABERMAS, Jürgen. (1984) "Was heißt Universalpragmatik". In: Vorstudien und Ergänzungen zur Theorie des kommunikativen Handelns. Frankfurt am Main: Suhrkamp.

HABERMAS, Jürgen. (1992) Faktizität und Geltung, Frankfurt am Main: Suhrkamp.

HABERMAS, Jürgen. (2019) Auch eine Geschichte der Philosophie. Berlin: Suhrkamp.

HABERMAS, Jürgen. (2020) "Von der formalen Semantik zur transzendentalen Pragmatik - Karl-Otto Apels ursprüngliche Einsicht", Topologik International Journal of Philosophy, Educational and Social Sciences, Vol 26, II, Dec 2019-Jan 2020a, 66-88.

HABERMAS, Jürgen. (2020) "Da semântica formal à pragmática transcendental: a ideia original de Karl-Otto Apel", ethic@-An international Journal for Moral Philosophy, v. 19, n. 3, p. 487-517, 2020 b.

HACKER, P. (1972) "Are Transcendental Arguments a Version of Verificationism?", American Philosophical Quarterly.

HARRISON, Ross. (1989) "Atemporal Necessities of Thought; or, How Not to Bury Philosophy by History". In: E. Schaper and W. Vossenkuhl (eds), Reading Kant, NY/Oxford, Basil Blackwell, pp. 43-54.

KÖRNER, Stephan. (1967) "The impossibility of Transcendental Deductions". In: The Monist 51, pp. 317-331.

NOBRE, M. e REPA, L. (Orgs.) (2012) Habermas e a Reconstrução, Campinas SP, Papirus.

PHILLIPS GRIFFITHS, A. (1966) "Ultimate Moral Principles: Their Justification". In: The Encyclopedia of Philosophy, NY/London, McMillan Publishing Co., Vol 8, pp.177-182.

PHILLIPS GRIFFITHS, A. (1969) "Transcendental Arguments". In: Proceedings of the Aristotelian Society, Suppl. 43, pp. 165-180.

RORTY, Richard. (1971) "Verificationism and Transcendental Arguments", Nous, pp. 3-14.

RORTY, Richard. (1979) "Transcendental Arguments, Self-reference and Pragmatism". In: P. Bieri, R. Hortsmann and L. Krüger (eds.), Transcendental Arguments and Science. Essays in Epistemology, Dordrecht (Holland), Reidel Publishing Company, pp. 77-103. 
SCHAPER, E. (1972) "Arguing Transcendentally," Kant-Studien 63, pp. 10116.

STRAWSON, P. F. (1966) The Bounds of Sense, London, Methuen \& Co. Ltd., 1978.

STROUD, Barry. (1968) "Transcendental Arguments". The Journal of Philosophy, LXV, pp. 241-256.

VELASCO, Marina. (2011) Ética do Discurso: Apel ou Habermas? Rio de Janeiro: Mauad. [2001].

WALKER, Ralph C. S. (1989) "Transcendental Arguments and Scepticism". In: E. Schaper and W. Vossenkuhl (eds), Reading Kant, NY/Oxford, Basil Blackwell, pp. 55-76.

WATT, A. J. (1975) "Transcendental Arguments and Moral Principles". In: Philosophical Quarterly, 25, pp. 40-57.

WELLMER, Albrecht. (1986) Ethik und Dialog. Frankfurt: Suhrkamp. 